\title{
PARTISIPASI GENERASI MUDA DALAM MEMBENTUK MASYARAKAT PEMILIH YANG CERDAS DAN DEWASA BERPOLITIK DI KECAMATAN JATINANGOR
}

\author{
Ari Ganjar Herdiansah ${ }^{1 *}$, Yusa Djuyandi ${ }^{1}$, Widya Setiabudi Sumadinata ${ }^{3}$ \\ ${ }^{1}$ Departemen Ilmu Politik, , Universitas Padjadjaran \\ ${ }^{3}$ Departemen Hubungan Internasional, Fakultas Ilmu Sosial dan Ilmu Politik Universitas Padjadjaran \\ E-mail: ari.ganjar@unpad.ac.id
}

\begin{abstract}
ABSTRAK. Pada 2019, Indonesia menggelar pemilihan umum yang kelima di era reformasi. Meskipun demokratisasi telah berlangsung selama dua puluh tahun, harapan masyarakat akan peningkatan kinerja pemerintah dan kesejahteraan dianggap belum optimal. Salah satu penyebabnya adalah rendahnya kualitas pemilih, di mana sebagian masyarakat pemilih masih mengedepankan faktor-faktor yang mendegradasi hasil pemilihan umum, seperti terlibat dalam jual-beli suara, mobilisasi isu-isu suku, agama, ras, dan antargolongan, dan menyebarkan berita bohong. Atas permasalahan tersebut, tim peneliti mengadakan kegiatan sosialisasi yang bertujuan untuk mendorong kelompok-kelompok pemuda di Kecamatan Jatinangor yang direpresentasikan oleh beberapa organisasi ekstra kampus untuk berpartisipasi dalam membentuk masyarakat pemilih yang cerdas dan dewasa berpolitik. Penekanan dalam kegiatan ini adalah elaborasi wacana melalui diskusi yang konstruktif yang berporos pada penguatan komitmen kelompok-kelompok pemuda terhadap demokrasi. Hasil dari kegiatan ini terwujud pada tercapainya kesepakatan di antara organisasi-organisasi ekstra kampus di Kecamatan Jatinangor untuk turut mencerdaskan masyarakat pemilih di sekitarnya demi meningkatkan kualitas pemilihan umum khususnya pada perhelatan pemilihan umum 2019.
\end{abstract}

Kata kunci: Political participation; Youth; Elections; Voters

ABSTRACT. In 2019, Indonesia held its fifth general election in the reform era. Even though democratization has been going on for twenty years, people's expectations for improving government performance and welfare are considered not optimal. One reason is the low quality of voters in elections, where some of them still prioritize factors that degrade the results, such as being involved in vote buying, mobilizing racist issues, and spreading hoaxes. Based on this problem, our team held a socialization program aimed at encouraging youth groups in Kecamatan Jatinangor which were represented by several extra-campus organizations to participate in forming smart and mature voters in the communities. The emphasis in this program is the elaboration of discourse through constructive discussion that pivot on strengthening the commitment of youth groups to democracy. The result of this program has manifested on the achievement of an agreement between extra-campus organizations in Kecamatan Jatinangor to educate the voters to improve the quality of elections, especially in the 2019 general election event.

\section{PENDAHULUAN}

Indonesia telah memasuki dua dekade demokratisasi terhitung sejak digulirkannya era reformasi pada 1998. Agenda utama dari reformasi politik pada waktu itu adalah menciptakan iklim politik demokratis yang tidak hanya menyerap aspirasi seluruh warga tetapi juga diharapkan dapat mendorong peningkatan kesejahteraan rakyat. Akan tetapi, sampai saat ini agenda tersebut dirasakan belum optimal. Salah satu penyebabnya adalah kualitas para pemilih yang masih rendah, di mana sebagian dari mereka masih ada yang terlibat dalam praktik jual beli suara (vote buying). Selain itu, pola hubungan klientilistik antara eliteelite partai dan konstituen juga mendorong terjadinya mobilisasi isu-isu suku, agama, ras, dan antargolongan (SARA) dalam pemilu demi memenangkan kandidat (Allen, 2015). Menjelang pemilihan umum (pemilu) 2019, dengan terjadinya polarisasi politik antara pendukung Jokowi dan pendukung Prabowo semakin meningkatkan friksi di media sosial yang diiringi fenomena penyebaran berita bohong (hoax) di tengah-tengah masyarakat (Herdiansah, Junaidi, \& Ismiati, 2017). Karena itu, upaya untuk menyadarkan masyarakat pemilih tentang tujuan dari demokrasi yakni terciptanya tatanan politik yang menyejahterakan dirasakan urgen untuk dilakukan.

Pemilu 2019 dilaksanakan secara serentak di mana pemilihan presiden (pilpres) dan pemilihan legislatif (pileg) dilakukan dalam waktu bersamaan. Pelaksanaan pemilu serentak membawa konskekuensi meningkatnya intensitas persaingan yang berdampak pada terjadinya pergesekan sosial. Sebagai provinsi dengan jumlah penduduk tertinggi dan lokasinya berdekatan dengan ibukota, Jawa Barat senantiasa menapaki dinamika politik berintensitas tinggi. Menjelang pemilu 2019 dampak persaingan politik di tingkat nasional sangat terasa di Jawa Barat. Dalam kasus aksi demonstrasi terhadap Basuki Tjahaja Purnama pada 2017, sebagian besar peserta aksi berasal dari Jawa Barat. Bahkan, peserta aksi dari Kab. Ciamis menunjukkan militansinya dengan berjalan kaki ke Jakarta untuk mengikuti aksi protes. Berdasarkan hasil survei Kompas yang dilaksanakan pada Juni 2018, Jawa Barat menempati posisi teratas sebagai provinsi dengan kecenderungan konservatisme tertinggi dibandingkan dengan provinsi-provinsi lainnya di Pulau Jawa. Dari hasil perhitungan survei, sebanyak 53 persen responden Jawa Barat dikategorikan konservatif politik, utamanya di Priangan barat dan Priangan timur (Kompas.id, 25 Juni 2018). Data Kementerian Koordinator Politik, Hukum, dan Keamanan juga mengungkapkan bahwa Jawa Barat merupakan provinsi dengan risiko konflik sosial yang tinggi (Republika.co.id, 11 Juni 2014).

Potensi kerawanan sosial pada pemilu di Jawa Barat menunjukkan bahwa masyarakat masih belum memahami makna dari pemilu dalam sistem politik 
demokrasi. Terlebih lagi, faktor-faktor sosial ekonomi di Jawa Barat yang kurang baik dapat menghambat partisipasi politik yang konstruktif. Penduduk Jawa Barat termasuk yang terpadat dengan jumlah 46.497 .175 jiwa penduduk tersebar di 26 kabupaten/kota, 625 kecamatan dan 5.899 desa/kelurahan. Namun, persebaran penduduk tidak merata dan terkonsentrasi di daerah perkotaan dan penyangga ibukota negara. Sekitar seperempat penduduk Jawa Barat tinggal di daerah penyangga ibukota negara, seperti Kab. Bogor, Kota Depok, Kab. Bekasi, dan Kab. Karawang. Sementara itu, sebanyak 18 persen penduduk tinggal di Bandung Raya (Kabupaten Bandung, Kabupaten Bandung Barat, Kota Bandung dan Kota Cimahi). Di samping itu, angka kemiskinan di Jawa Barat masih terbilang tinggi. Berdasarkan data Badan Pusat Statistik (BPS) pada Maret 2017, jumlah penduduk miskin di Jawa Barat berkisar 4 juta jiwa atau sekitar 9 persen dari keseluruhan jumlah penduduk (Jabarprov.go.id, 2017). Dengan adanya ketimpangan sosial ekonomi yang dapat mendorong ketidakpuasan publik dalam aksi-aksi massa, diperlukan langkah-langkah antisipatif agar masyarakat menyalurkan aspirasi politik secara konstitusional. Salah satunya adalah dengan mendorong masyarakat pemilih untuk lebih cerdas dan dewasa berpolitik, di mana hasil pemilu diharapkan dapat paralel dengan terwujudnya pemerintahan yang bersih, adil, dan menyejahterakan.

Salah satu upaya dalam meminimalisir dampak negatif tajamnya persaingan politik nasional jelang 2019 adalah dengan melakukan sosialisasi nilai-nilai yang dapat mendorong masyarakat untuk bersikap bijak dalam merespons berbagai isu politik, terutama yang bermuatan sentimen SARA. Perguruan tinggi sebagai lembaga akademik memiliki peranan untuk meningkatkan kesadaran masyarakat dalam mengikuti prosesproses politik dan pemilu. Melalui hasil penelitian terkait dengan masalah-masalah politik, insan intelektual dapat menyebarkan pengetahuan dan informasi kepada masyarakat luas agar terbangun kesadaran publik dalam memahami persoalan dan semangat untuk peduli terhadap kondisi sosial politik di sekitarnya.

Berdasarkan analisis kondisi di atas, tim peneliti menyelenggarakan kegiatan sosialisasi yang bertema partisipasi politik generasi muda dalam membentuk masyarakat pemilih yang cerdas dan dewasa berpolitik. Pengabdian kepada masyarakat merupakan usaha yang dilakukan oleh seseorang baik secara individu, bersamasama atau kelompok atau lembaga untuk membantu peningkatan taraf kehidupan masyarakat yang dibantu sesuai dengan misi yang diembannya yaitu pengamalan ilmu pengetahuan, teknologi dan seni langsung pada masyarakat dilaksanakan secara institusional dan profesional, sebagai tanggungjawab luhur perguruan tinggi dalam usaha mengembangkan kemampuan masyarakat sehingga dapat mempercepat tercapainya tujuan pembangunan nasional (Sudin, 2004). Kegiatan ini dilakukan di Kecamatan Jatinangor, suatu kawasan kampus yang ditempati oleh empat perguruan tinggi, yakni Universitas Padjadaran (Unpad), Institut Teknologi Bandung (ITB), Institut Koperasi Indonesia (Ikopin), dan Institut Pemerintahan Dalam Negeri (IPDN). Kawasan kampus dinilai strategis untuk melakukan kegiatan ini karena para mahasiswa dapat mengarahkan aktivitasnya untuk turut membangun masyarakat yang paham menggunakan hak pilihannya pada pemilu 2019. Selain itu, para mahasiswa dapat mendiseminasikan pengetahuan dan wawasan tentang berpolitik yang cerdas dan dewasa ke lingkungan tempat asalnya. Beberapa organisasi mahasiswa ekstra kampus yang merepresentasikan kelompok pemuda antara lain Himpunan Mahasiswa Islam (HMI), Pergerakan Mahasiswa Islam Indonesia (PMII), Kesatuan Aksi Mahasiswa Muslim Indonesia (KAMMI), dan Keluarga Mahasiswa Nahdlatul Ulama (KMNU). Pada saat acara, terdapat satu organisasi yang tidak dapat hadir yaitu Gerakan Mahasiswa Nasionalis Indonesia (GMNI), akan tetapi mereka turut berkontribusi di luar acara. Di samping itu, panitia kegiatan juga mengundang kalangan jurnalis yang memberitakan pengetahuan dan konten diskusi secara luas melalui media massa, antara lain dari TVRI Jawa Barat, Metrotv, dan Tribun Jabar.

\section{METODE}

Kegiatan ini dilakukan melalui pendekatan sosialisasi, yang di dalamnya terdiri kegiatan ceramah dari tim dosen Unpad (tim peneliti), penyampaian pandangan dari tiap-tiap organisasi pemuda, tanya jawab dan diskusi, serta deklarasi kesepakatan untuk berpartisipasi membentuk masyarakat pemilih yang cerdas dan dewasa berpolitik. Karena kegiatan ini juga terintegrasi dengan Kuliah Kerja Nyata (KKN) mahasiswa Unpad, sebelum mengadakan acara sosialisasi para mahasiswa melakukan pemetaan masalah terkait isu-isu sosial politik dan peran pemuda bersama-sama dengan perwakilan organisasiorganisasi ekstra kampus selama kurang lebih satu bulan. Tahapan pemetaan masalah dimulai pada bulan Oktober 2018, sementara itu kegiatan sosialisasi dilaksanakan pada 22 November 2018 yang berlokasi di kampus FISIP Unpad Jatinangor. Pemetaan masalah menjadi landasan bagi poin-poin diskusi pada acara sosialisasi. Pada kegiatan sosialisasi, di sesi pertama, tim dosen Unpad menyampaikan materi tentang kondisi eksisting kontes politik menjelang pemilu 2019. Pada sesi kedua, perwakilan dari HMI, KAMMI, GMNI, dan IPNU menyampaikan pandangan tentang masalah sosial politik terkait pemilu 2019 dan bagaimana sikap serta pandangan mereka terkait isu-isu yang menyertainya. Pada sesi berikutnya, para peserta yang sebagian besar berasal dari anggota organisasi pemuda di Jatinangor dan mahasiswa Unpad melakukan tanya jawab dan diskusi. Pada sesi terakhir, hasil kesepakatan yang diraih selama proses diskusi dirumuskan dalam bentuk deklarasi pernyataan bersama seluruh organisasi ekstra kampus di Jatinangor 
untuk berkomitmen turut mencerdaskan masyarakat pemilih di sekitarnya. Kegiatan ini diliput dan diberitakan oleh beberapa media massa, seperti TVRI Jawa Barat, Metrotv, dan Tribun Jabar sehingga informasi dan pengetahuan dari kegiatan ini mendapatkan diseminasi yang luas bukan hanya bagi masyarakat di Jatinangor tetapi juga di seluruh daerah Jawa Barat.

\section{HASIL DAN PEMBAHASAN}

\section{Pemetaan Masalah dari Perspektif Organisasi Pemuda}

Pada tahap pemetaan masalah, seluruh organisasi mahasiswa ekstra kampus di Jatinangor memahami bahwa kondisi sosial politik yang terjadi menjelang pemilu 2019 mengandung beberapa masalah. Secara umum, masalah utama yang mereka sadari adalah berlangsungnya persaingan politik yang kurang sehat karena diwarnai oleh isu-isu SARA oleh berbagai pihak/partisan. Meskipun demikian, mereka melihat masyarakat di tingkat bawah masih kondusif dan tidak terlalu terbawa oleh friksi-friksi di tingkat elite dan partisan. Himpunan Mahasiswa Islam berharap bahwa kontes pemilu 2019 dapat dilakukan dengan memenuhi prinsip jujur, adil, dan damai. Mereka menyatakan kesiapan untuk mengawal proses pemilu secara damai dan tidak berpihak pada salah satu kontestan. Permasalahan lain yang dirasakan oleh organisasiorganisasi ekstra kampus adalah adanya kekhawatiran mengemukanya sentimen identitias atau SARA akibat persaingan dan friksi politik yang semakin ketat. Para kandidat ataupun tim sukses sudah memperlihatkan gejala melakukan berbagai cara untuk mempengaruhi opini publik, termasuk menyisipkan isu-isu sosial keagamaan dan melakukan mobilisasi pendukung berdasarkan identitas kelompok tertentu. Harapannya, masyarakat tidak terbawa pada wacana-wacana yang mengandung sentimen SARA dan berfokus pada program kerja para kandidat secara substantif.

Beberapa organisasi, salah satunya GMNI, berpandangan bahwa polarisasi identitas yang mengiringi kontes pemilu 2019 tidak terlepas dari bagian strategi setiap tim kandidat dalam membangun branding. Di tingkat masyarakat, polarisasi identitas sudah terlihat dengan pengelompokkan kubu-kubu pendukung berdasarkan lingkungan sosialnya (social milieu), misalnya di kalangan Islam sebagian ada yang secara menonjol memperlihatkan dukungannya ke Prabowo dan sebagaian menunjukkan sokongannya kepada Jokowi. Pengelompokkan tersebut dapat diamati berdasarkan garis organisasi dan aliran. Akan tetapi, polarisasi identitas yang terjadi di masyarakat dapat disikapi dengan bijak di kalangan mahasiswa. Dengan bekal insting intelektual, para mahasiswa mampu mengelola perbedaan pandangan dan pilihannya. Mereka tidak ikut-ikutan dalam friksi dan polarisasi pendukung pilpres 2019 di lingkungan kampus. Meskipun arah dukungan GMNI secara tidak resmi relatif mudah dilihat karena memiliki kedekatan dengan partai politik, tetapi mereka tetap memberikan dukungan secara rasional bukan atas dasar kebencian.

Sementara itu, KAMMI melihat polarisasi yang terjadidimasyarakatmenjelangpemilumerupakanhalyang lumrah. Fenomena potensi perpecahan akibat polarisasi dukungan terhadap kandidat pilpres 2019 menurutnya memang terlihat di beberapa kelompok masyarakat, tetapi tidak terlihat pada sebagaian masyarakat lainnya. Secara institusi, meskipun organisasi KAMMI dikenal memiliki kedekatan dengan salah satu partai politik Islam, mereka bersikap netral atau tidak berpihak pada kandidat manapun di pilpres 2019, serta memberikan kebebasan kepada para anggotanya dalam menentukan pilihannya. Dalam menanggapi banyaknya berita simpang siur yang dapat memperkeruh kerukunan antargolongan di masyarakat, KAMMI menekankan perlunya filter bagai berita-berita yang beredar dan senantiasa mengecek ulang kebenaran suatu berita. Karena, belum tentu berita, terutama yang menyebar melalui pesan berantai, berdasarkan pada fakta melainkan rekayasa yang dibuat oleh pihak yang tidak bertanggung jawab. Organisasi ini menerapkan prosedur untuk memeriksan fakta-fakta menyeluruh terkait suatu isu sebelum memberikan tanggapan atau memuatkannya ke dalam website organisasi.

Dalam kegiatan ini, terdapat organisasi ekstra kampus yang antusias berpartisipasi yang semuanya berafiliasi dengan organisasi massa terbesar di Indonesia, yaitu Nahdlatul Ulama. Mereka adalah PMII dan KMNU Cabang Jatinangor. Bagi PMII, pelaksanaan pemilu serentak yang baru digulirkan sejak 2015 terdapat kelebihan dan kekurangannya. Salah satunya adalah minimnya pasangan calon presiden dan wakil presiden yang berkompetisi di pilpres 2019 yang menyebabkan polarisasi politik tidak terhindarkan. Sama halnya dengan PMII, mereka berpandangan bahwa polarisasi dalam pemilu merupakan fenomena yang wajar terjadi karena telah berlangsung sejak periode-periode sebelumnya. Mereka menilai bahwa polarisasi tersebut akan berkurang setelah pemilu telah usai. Dampak polarisasi, menurut perwakilan PMII, cenderung terjadi di lingkungan elite-elite yang sedang bertarung. Di tingkat akar rumput, polarisasi tersebut kurang terasa. Tetapi, para elite yang sedang terlibat dalam kompetisi elektoral terlihat menggembar-gemborkan polarisasi, sehingga seakan-akan dampaknya terlihat luas. Bagi organisasi, bersikap netral dalam pilihan pilpres 2019 merupakan prinsip yang penting dijaga, sehingga selaras dengan nilal moderat dan berpihak pada kepentingan masyarakat umum. Polarisasi di kalangan partai politik dan tim sukses dipandang tidak berimbas pada hubungan antarorganisasi, karena mereka memiliki organisasi payung Komite Nasional Pemuda Indonesia (KNPI). Organisasi KNPI tersebut juga berfungsi sebagai wadah bagi tiap-tiap organisasi di dalamnya untuk melakukan musyawarah apabila terjadi masalah atau isu yang penting untuk didiskusikan. 
Organisasi mahasiswa dari kalangan Nahdlatul Ulama lainnya, KMNU, berpandangan bahwa isu yang memprihatinkan menjelang pemilu 2019 adalah penyebaran berita-berita bohong yang massif. Berita-berita bohong pada umumnya ditujukan untuk memojokkan atau menjelek-jelekan salah satu pasangan kandidat pilpres atau biasa disebut kampanye hitam (black campaign). Mereka menambahkan bahwa praktik semacam itu akan berdampak besar tidak hanya dalam konteks pemilu, tetapi juga di luar pemilu. Pencitraan negatif terhadap kandidat pada akhirnya senantiasa berujung pada pembentukan selera masyarakat yang subjektif. Misalnya, tindakan yang dilakukan oleh pemerintah dilihat baik atau buruk bukan berlandaskan pada fakta-fakta, tetapi pada suka atau tidak suka seseorang dalam menilai sosok yang menjalankan pemerintahan. Secara keorganisasian, KMNU bersikap netral dalam pemilu 2019 dan memberikan kebebasan kepada para anggotanya untuk memilih partai politik dan pasangan kandidat pilpres. Meskipun terdapat perbedaan pilihan politik baik di kalangan internal maupun dengan organisasi-organisasi lainnya di lingkungan Jatinangor, KMNU menyikapinya secara dewasa. Pembahasan isuisu politik dengan berbagai organisasi seperti, PMII, HMI, dan lainnya lebih berfokus pada fakta-fakta dan dari kacamata akademis.

\section{Tabel 1. Pemetaan Masalah}

\begin{tabular}{ll}
\hline \multicolumn{1}{c}{ Masalah } & \multicolumn{1}{c}{ Solusi/saran } \\
\hline Sentimen identitas & $\begin{array}{l}\text { Menghimbau dan memberikan contoh } \\
\text { agar diskusi politik diarahkan pada isu-isu }\end{array}$ \\
& $\begin{array}{l}\text { substantif seperti program kerja ketimbang } \\
\text { isu-isu identitas }\end{array}$ \\
Polarisasi & Membendung supaya polarisasi politik \\
& hanya berlangsung dalam konteks kompetisi \\
& pemilu, tidak berdampak pada aspek \\
& kehidupan lain terutama yang dapat merusak \\
& sendi-sendi kerukunan di masyarakat \\
Penyebaran hoax & $\begin{array}{l}\text { Memeriksa ulang setiap berita secara } \\
\text { komprehensif sebelum disebarkan atau } \\
\text { dibicarakan lebih lanjut }\end{array}$ \\
Kampanye hitam & $\begin{array}{l}\text { Menghimbau kepada masyarakat untuk tidak } \\
\text { terpancing melakukan tindakan-tindakan }\end{array}$ \\
& $\begin{array}{l}\text { yang berdampak pada perilaku negatif, } \\
\text { seperti menjelek-jelekan pasangan kandidat } \\
\text { pilpres }\end{array}$ \\
\hline
\end{tabular}

\section{Kesepakatan dan Deklarasi Membangun Masyarakat Pemilih yang Cerdas}

Setelah melakukan kegiatan diskusi antarorganisasi pemuda dengan seluruh hadirin acara sosialisasi, para peserta diskusi menyepakati beberapa poin yang pada intinya mereka berkomitmen untuk berpartisipasi membangun masyarakat pemilih yang cerdas dan dewasa berpolitik menjelang pemilu 2019. Adapaun hasil kesepakatan yang telah dicapai melalui elaborasi wacana dan diskusi dengan beberapa organisasi mahasiswa ekstra kampus adalah sebagai berikut:

1. Kami sepakat bahwa kami akan berperan serta mengajak masyarakat agar menciptakan situasi yang aman, damai dan harmonis terutama di tahun politik ini.
2. Kami turut berupaya membangun suasana pemilu yang mencerdaskan masyarakat bersandar pada nilainilai demokrasi Pancasila

3. Kami berkomitmen untuk menyosialisasikan kepada masyarakat agar menggunakan hak-hak politiknya secara dewasa dan bertanggung jawab.

4. Kami menghimbau agar para elite politik menjalani kompetisi pemilu secara sehat dengan memperhatikan etika, moral, dan nilai kebangsaan sehingga kerukunan dan kedamaian bangsa Indonesia tetap terjaga.

\section{SIMPULAN}

Kegiatan pengabian ini diharapkan dapat mendorong para generasi intelektual muda untuk lebih berkiprah di masyarakat dalam mengatasi berbagai persoalan sosial yang diakibatkan kompetisi pemilu 2019. Dalam dinamika politik yang tajam dan panas, utamanya di Jawa Barat, para mahasiswa sebagai insan akademik dapat memberikan pencerahan kepada masyarakat untuk tetap bersikap rasional dan moderat dalam menyikapi perkembangan isu-isu politik. Kegiatan semacam ini merupakan salah satu bentuk pendidikan politik yang konstruktif dan diharapkan turut membangun sikap masyarakat dalam berpolitik secara cerdas dan dewasa; tidak termakan isu-isu yang memuat sentimen SARA, percaya dan turut menyebarkan hoax, dan menjelekjelekan lawan politiknya. Semoga kegiatan sosialisasi ini dapat mewujudkan kehidupan demokrasi yang sesuai dengan nilai-nilai Pancasila, khususnya di Jatinangor dan umumnya di Jawa Barat.

\section{UCAPAN TERIMAKASIH}

Tim penulis mengucapkan terima kasih kepada Universitas Padjadjaran yang telah menyokong pendanaan kegiatan Pengabdian Pada Masyarakat melalui program Hibah Internal Unpad (HIU) 2018.

\section{DAFTAR PUSTAKA}

Allen, N. W. (2015). Clientelism and the Personal Vote in Indonesia. Electoral Studies, 37, 73-85. https://doi. org/10.1016/j.electstud.2014.10.005

Brownell, S. E., Price, J. V., and Steinman, L. (2013). Science communication to the general public: why we need to teach undergraduate and graduate students this skill as part of their formal scientific training. J. Undergrad. Neurosci. Educ. 12, E6-E10.

Burns, T. W., O’Connor, D. J., and Stocklmayer, S. M. (2003). Science communication: a contemporary definition. Public Underst. Sci. 12, 183-202. doi: 10.1177/09636625030122004

Herdiansah, A. G. (2016). Public Policy and Religious Conflict in Indonesia: The Case of Ahmadiyah. 
Jurnal Wacana Politik, Vol. 1(1), 53-63. https://doi. org/10.24198/jwp.vli1.10541

Herdiansah, A. G., Junaidi, \& Ismiati, H. (2017). Pembelahan Ideologi,Kontestasi Pemilu, dan Ancaman Keamanan Nasional: Spektrum Politik Indonesia Pasca 2014? Jurnal Wacana Politik, 2(1).

Jabarprov.go.id. (2017). Penduduk, Sumber: http:// jabarprov.go.id/index.php/pages/id/75 [Diakses pada tanggal 29 Agustus 2018].

Kompas.id. (2018). Keunikan Peta Politik Jawa Barat 11 Juli 2018, Sumber: https://kompas.id/baca/ riset/2018/07/11/keunikan-peta-politik-jawabarat-1/ [Diakses pada tanggal 27 Agustus 2018].

Kompas.com. (2017). Lebih dari 4 juta warga di Jawa Barat hidup dalam Garis Kemiskinan (13
Oktober 2017). https://regional.kompas.com/ $\mathrm{read} / 2017 / 10 / 13 / 14571241 /$ lebih-dari-4-jutawarga-jawa-barat-hidup-dalam-garis-kemiskinan

Kompas.id. (2018). Ceruk Konserfatif dan Moderat di Pilkada (25 Juni 2018). https://kompas.id/ baca/polhuk/2018/06/25/ceruk-konservatif-danmoderat-di-pilkada/

Republika.co. (2014). Jawa Barat Berpotensi Konflik SARA (11 Juni 2014). https://www.republika. co.id/berita/nasional/jawa-barat-nasional/14/06/11/ n6zuol-jawa-barat-berpotensi-konflik-terkait-sara

Sudin. (2004). Pengabdian Kepada Masyarakat Bagi Perguruan Tinggi Agama Islam . Jurnal Aplikasi llmu-ilmu Agama, Vol. V, No. 2 